Lenntuise dos anderen 'Tuile les Systens un chemischen Methoden verdanken. Wir müssen also fragen, welche Atomgervichte wir den uns chemisch als eimheitliche Elemente erscheineriden Plejaden zuschreiben würden, wenn wir auch hies nur chemische Methoden zur Verfügung hätten. Wir würden dann auch hier ein solches Element aus den Mineralien abscheiden und das Atomgewicht experimentell bestimmen. Wir würden einen Mittelwert bekommen. Auf diesen Mittelwert wïrden natürlich die verschiedenen Elemente des Gemisches einen verschiedenen Einfluß ausüben, je nach den relativen Mengen, in denon die einzelnen Bestandteile das Gemisch zusammensetzen. Es ist nun leicht einzusehen, dab ein Element in um so kleineren Mengen vorkommt; je kurzlebiger es ist. Die Beeinflussung des 'mittleren Atomgewichts durch die einzelnen Komponenten hängt also von deven Lebensdauer ab. Ist eines vou den Elementen einer Plejade viel langlebiger wie die anderen, und das trifft in der Tat für alle bekannten Plejaden zu (die Halbwertzeiten. der Elemente sind in der Tabelle 2 angegeben), so kann man, ohne einen wesentlichen Fehler zu begehen, sein Atomgewicht als das in das allgemeine periodische System passende ansehen. Wenn wir auf diese Weise verfahren, so bekommen wir für die mittleren Atomgewichte der Plejaden Werte, welche den in der Tabelle 2 fett gedruckten Elementen gehören, und man sieht, da ̇̀ das Atomgewicht von rechts nach links regelmäBig abnimmt, so wie in den übrigen Reihen des periodischen Systems; es verschwindet somit auf diese Weise vollkommen die wirkliche Cnregelmäßigkeit der Atomgewichte, die die vielen Elemente verursachen. Also auch in dieser Hinsicht erhalten wix eine vollkommene Anpassung an die Tabelle des periodischen Systems.

Die volle Klarheit über die Stellung der Radioelemente im periodischen System ist erst am $\mathrm{An}$ fang des vorigen Jahres erzielt worden, und zwar durch die unabhängigen Arbeiten von $A$. Russe $l^{1}$ ) und vom Verfasser ? ) und die etwas später erschienene Abhandlung ron $F$. $S o d d y^{3}$ ). Historisch verdient es aber erwähnt zu werden, dab schon im Jahre 1909 D. Strömholm und The Svedberg ${ }^{4}$ ) den richtigen Weg zur. Lösung dieses Problems angedeutet haben, indem sie erkannten, daB Thorium $X$ und Aktinium. $X$ dem Radium vollkommen auch in quantitativer Hinsicht gleichen und ihnen die gleiche Stelle im periodischen System mit diesem zuwiesen. Boddy schloß sich ${ }^{5}$ ) dieser Auffassung an und behandelte von diesem Standpunkt die in mehreren Fällen festgestellte Untrennbarkeit der Radioelemente voneinander und von gewöhnlichen Elementen ${ }^{\mathrm{b}}$ ). Die angegebene Tabelle 2 ist vom

1) Chem. News 107, 49 (1913).

2) K. Fajans, Physikal. Ztsehr. 14, 131 u. 130 (1913).

a) Chem. News. 107, 97 (1913).

4) Z. f. anorg. Ch. 61,$338 ; 63,197$ (1909).

5) Journ. Chem. Soe. 99,72 (1911).

6) Chemie d. Radioelemente, 1911.
Verlassed und danu ron soddy inhaltich identiseh, der form nacl etwas verschieden aufgestellt worden.

(Schlup folgt.)

\section{Die Lehre Abderhaldens von den Abwehrfermenten.}

Ton Dr. If. Sioli, Bonn,

Oberarzt der Pror-Heil- und Pflegeanstalt.

Die Abderhaldenschen Forschungen ${ }^{\mathbf{1}}$ ) über die Abwehrfermente des tierischen Organismus haben in breiten Kreisen eine auBerordentliche Beachtung gefunden, so daB es angebracht erscheint, an dieser Stelle die Lehre Abderhaldens und einiges ihrer Ergebnisse kurz su skizzieren.

Es handelt sich um das Verhalten des Organismus beim Eintritt eines von Abderhalden treffend „blutfremden" oder "plasmafremden" genannten Materials in die Blutbahn.

Abderhalden geht aus von den Vorgängen der Verdauung; dabei werden dem Organismus körperfremde Nahrungsstoffe gereicht, die Verdauung bezweckt, diese in körpereigene zu verwandeln; das wird bewirkt durch die Fermente des Verdauungskanals und seiner Anhangsapparate. Erst nachdem durch diese Fermente die Nahrungsstoffe soweit verändert sind, dab sie blut- resp. plasmaeigen geworden sind, werden sie in das Blutplasma aufgenommen und als ein passendes und konstantes Gemisch den Körperzellen zugeführt.

Wird nun einem Organismus mit Umgehung: des gewohnten Weges des Darmkanals ein fremder, nicht ohne weiteres ausscheidbarer $\mathrm{Nah}$ rungsstoff unmittelbar in die Blutbahn gebracht (parenterale Zufuhr), so treten im Blut Fermente auf, die den Stoff abzubauen vermögen und so die versäumte Verwandlung des körperfremden Stoffes in einen körpereigenen nachholen (Versuche von Weinland, Abderlalden $\mathrm{u}$, a. mit parenteraler Zufuhr von Rohrzucker, Proteinen und Fettstoffen). Diese Fermente wurden ron Abderhalden anfänglich mit dem von Heilner gegebenen Namen Schutzfermente, später Abwehrfermente bezeichnet. Der Vorgang entspricht im Prinzip der Antikörperbildung bèi Zuführung von Infektionservegern und anderem körperfremden $\mathrm{Ma}$ terial.

Die Zellen und Organe des tierischen Körpers haben thren spezifischen Bau mit besonderen Funktionen und einem besonderen Stoffwechsel; sie müssen imstande sein, aus dem gleichartigen Gemisch des Blutes, das ihnen an sich noch zellfremd resp. organfremd ist, die ihnen passenden Stoffe zu entnehmen und zu zelleigenen resp. organeigenen zu machen. Die Organzellen selbst sind alsdann blutfremd resp. plasmafremd gewor-

1) Emil Abderhalden, Schutzfermente des tierischen Organismus 1912, 2. und 3. Auflage Abwehrfermente usw. 1013. 
den; andererseits müssen die Organzellen imstande sein, nur Produkte dem Kreislauf zu übergeben, die nicht blutfremd sind. $\mathrm{Nux}$ so ist die notwendige konstante Mischung des Blutplasmas gewährleistet.

Es entstand so für Abderhalden die Fragestellung; ob, wenn infolge besonderer Verhältnisse aus den Organen des Körpers Stoffe in das Blut eintretén, die zwar körpereigen, aber blutfremd sind, der Organismus mit Bildung von Fermenten antwortet, welche die blutfremden Stoffe in bluteigene verwandeln können. Der Nachweis eines entsprechenden Fermentes im Blut bedeutet dann den Eintritt eines besonderen blutfremden Stoffes in die Blutbahn.

Zum Nachweis der Fermente hat Abderhalden zwei Methoden ausgearbeitet. Das Prinzip beider ist, daB das zu untersuchende Serum zusammengebracht wird mit in bestimmter Weise präparierten Organen; wenn ein Abbau des Organes erfolgt, so wird daraus geschlossen, daß das Serum die normalerweise nicht vorhandenen Fermente enthält. Dex Nachweis ist also ein indirekter. Bei der sogenannten optischen Methode wird das Serum mit einer aus den Organen hergestellten Peptonlösung zusammengebracht und im Polarisationsapparat das Auftreten oder Ausbleiben einer Drehungsänderung des Gemisches bèbachtet. Bei dem sogenamnten Dialysierverfahren wird das Serum mit koaguliertem Organeiweiß in einem Dialysierschlauch aus besonderer Membran zusammengebracht, durch die nicht Eiweib, aber die nächste Abbaustufe, die Peptone diffundieren; es handelt sich dann darum, das Auftreten oder Fehlen von Peptonen in einer den Schlauch umgebenden Außenflüssigkeit nachzuweisen. Beide Methoden erfordern peinlichste Sorgfalt.

Auf Grund der skizzierten Uberlegungen wurde die Serodiagnostik der Schwangerschaft in Angriff genommen. Die bereits ältere Lehre der Zottendeportation (Schmorl, Veit, Weichardt), daß Chorionzotten, d. h. Teile des kindlichen Anteils der Placenta, während der Sehwangerschaft in den mütterlichen Kreislauf gelangen, legte hier die Untersuchung nahe. Es zeigte sich, daß während der Schwangerschaft im Blute Abwehrfermente kreisen, die Placenta abbauen. Von vornherein wurde nur ein zeitweiliger Nachweis der Fermente erwartet, da es unwahrscheinlich ist, daß sich dauernd Chorionzotten loslösen und Fermente nur eine beschränkte Zeit nach Einfuhr körperfremden Materials rorhanden sind. Ts zeigte sich aber, daß das Sohwangerenserum bereits kurz nach der Befruchtung (ca. 8 Tage), während der ganzen Schwangerschaft und ca. 14-21 Tage dartiber hinaus PlacentaeiweiB abbaute, daB weiterhin auch das Blut trächtiger Stuten, deren Placentakreislauf eine Chorionzottenverschleppung wohl unmöglich macht, die Abrvehrfermente enthält. In der Zottenverschleppung allein konnte somit das Auftreten der Abwehrfermente nicht begründet sein. Man kann sich aber wohl vor- stellen, daB die Placenta in gewissem Sinne dem mütterlichen Organismus neuartig ist und das Blut daher von deren Zellen mit blutfremden Stoffen beladen wird, oder daB durch die Lebhaftigkeit der Stoffwechselvorgänge bei der Entwicklung der Placenta deren Zellen nicht imstande sind, ihre Produkte bis zu bluteigener Beschaffenheit abzubauen.

Die Fortführung der Versuche führte $\mathrm{zu}$ einer weiteren Überraschung: der Spezifizität der Fermente; dieselbe war nicht erwartet worden, denn die parenterale Zufuhr von Nahrungsstoffen bewirkt nux eine beschränkte Spezifizität der Abwehrfermente, die imstande sind je nachdem Gruppen von Proteinen oder Kohlehydraten zu zerlegen. So wurde bei der Schwangerschaftsreaktion zunächst auch an ein allgemeineres proteolytisches Ferment gedacht. Es stellte sich aber für Abderhalden heraus, daß das Schwangerenserum andere Gewebe als Placenta nicht abbaut und daß z. B. das Serum voil Carcinomkranken wohl Carcinomgewebe, aber nicht Placenta abbaute. Derartige Erfahrungen drängten zur Annahme streng spezifischer Abwehrfermente und eröfneten Perspektiven auf die Untersuchung der mannigfaltigsten Veränderungen des Körpers, auf die Neubildungen und die Funktionsprüfung der Organe. Im einzelnen Fall muB der Nachweis eines Abwehrferments anzeigen, dab von einem entsprechenden Organ aus blutfremde Stoffe an das Blut abgegeben werden, also eine Neubildung, ein Zerfall, oder eine Funktionsstörung vorliegt.

Seitdem Abderhalden seine Methoden allgemeiner wissenschaftlicher Forsehung übergeben hat, sind sie unter der Teitung der Abderhaldenschen Gedanken in umfangreicher Weise gebraucht worden und haben die mannigfaltigsten Ergebnisse gebracht. Die Schwangerschaftsdiagnose (über die Heimann bereits in Heft 12, 1913, der Naturwissenschaften berichtet hat) ist an einer in die Tausende gehenden Zahl von Fällen bestätigt, bei zahlreichen Carcinomkranken wurde ein Carcinomgewebe abbauendes Forment, bei den Fällen von Basedowscher Erkrankung ein Abwehrferment gegen Schilddrüsengewebe, besonders gegen das Gewebe pathologisch veränderter Schilddrüsen, gefunden, bei Tnfektionskrankheiten wurden Abwehrfermente gegen das Eiweis von entsprechenden Erregerkulturen festgestellt, bei bestimmten Klasser von Geisteskranken wurde durch Abbau von Gehirnsubstanz, bei anderen durch Abbau von Gehirn, Geschlechtsdrüsen und Schilddrüse ein charakteristischer Befund beschrieben.

Derartige Befunde kömen zu Eirkenntnissen von gxößter Wichtigkeit führen:' Umfang der durch eine Krankheit gesetzten Schädigungen Beziehungen der einzelnen Organe zueinander und der Schädigungen bestimmter Organe auf andere, der Entstehungsmechanismus bisher dunkler Veränderungen, der Erfolg von Radikaloperationen bösartiger Geschwülste u. a. m. können durch 
Auftreten und Verschwinden von Abwehrfermenten beleuchtet werden.

Es ist allerdings $z u$ bemerken, daB eine, wenn auch kleinere Zahl von Forschern auf Grund ihrer Versuche der Abderhaldenschen Lehre nicht zustimmt. Einwände richten sich einerseits gegen die Methode des Nachweises der Abwehrfermente, ganz besonders aber gegen die Spezifizität der Abwehrfermente. Dje Einwände werden durchgehend auf Grund des Dialysierverfahrens erhoben. Ob die abweichenden Befunde auf den natürlichen Kinderkrankheiten neuer Methoden beruhen, oder doch so viel Richtiges enthalten, daf sie zu einer Einschränkung der praktischen Verwertung der Lehre führen werden, können erst noch lange fortgeriuhrte Untersuchungen, ganz besonders mit der optischen Methode, lehren, über die seinerzeit zu berichten sein wird.

\section{Die Zisternen der Bromeliazeen.}

\author{
Dr. F. Moewes, Berlin.
}

In der Szenerie der amerikanischen Tropenwälder bilden die auf den Bäumen hausenden Bromeliazeen ein charakteristisches Element. Es sind Monokotylen mit meist kurz bleibendem Stengel und groken Blattrosetten, in ihrem typischen Habitus den Agaven vergleichbar. Die Blüten stehen in Trauben, Rispen oder Ähren und haben drei Kelchblätter, drei Blumenblätter, sechs Staubblätter und drei Karpelle, die einen bald unterständigen, bald halb oder ganz oberständigen Fruchtknoten bilden. Die Wurzeln sind wenig entwickelt, fehlen zuweilen auch ganz. Für die Ernährung der Pflanze sind sie so gut wie bedeutungslos; sie dienen nur der Befestigung des Epiphyten auf seinem Wirtsbaum. Die Aufnahme der Nahrung erfolgt vielmehr durch die Blätter, an deren Grunde sich Wasser sowie Pflanzen- und Tierreste ansammeln; vermittels eigenartiger Schuppenhaare an der inneren Blattoberfläche werden aus der so gebildeten Nährlösung die Stoffe aufgesaugt, deren die Pflanze zu ihrer Erhaltung bedarf. Utbrigens gibt es auch eine Anzahl von Bromeliazeen, die auf der Erde wachsen; so das praktisch wichtigste aller Mit glieder der Familie, die Ananas.

Dem trefflichen $A . F . W$. Schimper verdanken wir die ersten genaueren Untersuchungen übex die Nahrungsaufnahme der epiphytischen Bromeliazeen. Später haben sich Mez; Tietze, Aso mit dem Bau und der Funktion der absorbierenden Schuppenhare beschäftigt. AuBerdem liegen zahlreiche Angaben über die in den Wasseransammlungen der epiphytisehen Bromeliazeen lebenden Tiere vor. Bereits Fritz Müller hatte 1879 einen Muschelkrebs beschrieben, der nur in den Zistemen dieser Epiphyten, nicht im Wasser des Erdbodens zu finden war. Seitdem sind Tiere der verschiedensten Klassen und Ordnungen bis hinauf zu den Batrachiern als Mitglieder der Bromeliazeenfouna festgestellt worden. Man kannte ihrer bisher etwa 100 Arten. Die Nachforschungen, die L. Picado in Costa Rica angestellt hat, bringen ihre Zahl auf 250, worunter 49 ganz neu $\sin \mathrm{d}^{1}$ ).

Pieado vergleicht die Basis der Blatrosette einer Bromeliazee mit 2 Kegeln, von denen einer in den anderen gestellt ist. Der äubere wird von den alten Blättern gebildet, die ,schlecht eingeschachtelt" erscheinen, der innere besteht aus der Gesamtheit der lebenden, ,gut eingeschachtelten" Blätter. Dieser innere Teil allein ist imstande, das Wasser zurückzuhalten; der äußere dagegen enthält kein Wasser, sei es, weil er es ausflieben läbt, oder weil die Enden der inneren Blätter sich wie ein Dach darüberlegen und den Regen nicht hineingelangen lassen. Den inneren Teil bezeichnet Picado als Aquarium, den äuBeren als Terrarium. Das Terrarium bildet ein zusammenhängendes Ganzes, da von den alten Blättern höchstens die Basen erhalten bleiben; es ist erfüllt mit den Absätzen aus dem früher ron den Blättern angesammelten Wasser nebst den Bruchstücken toter Blätter, und da diese Stoffe einer langsamen Zersetzung anheimfallen, so entsteht aus ihnen ein richtiger Humus. Das Aquarium ist dagegen in der Regel in eine Reihe kleiner Abschnitte gegliedert, die unter sich nicht zusammenhängen, so dab das Wasserniveau in jedem verschieden sein kann.

Das in den "Aquarien" oder Zisternen") angesammelte Wasser stammt nicht blok von dem Regen, sondern auch von der täglichen Kondensation des atmosphärischen Wassers. Daher enthalten die Bromeliazeen auch in der Trockenzeit Wasser, und hierdurch (von anderen Eigenschaften abgesehen) unterscheiden sich diese "mares broméliennes" von den irdischen Lachen und Tumpeln (mares terrestres), die dann aus. getrocknet sind. Die Wassermenge, die zwischen den Blättern gewisser Bromeliazeen zurückgehalten wixd, kann an 201 betragen. Die Pflanzenreste, die in die Aquarien fallen, und die Tiere, die darin umkommen, faulen nicht; diejenigen Stoffe, die nicht von den Blattschuppen absorbiert werden, bilden schlieblich eine leichte, braune Masse, die an neugebildeten Torf erinnert.

Das Ausbleiben der Fäulnis und die Reinheit des Wassers in den Zisternen der epiphytischen Bromeliazeen ist eine sehr auffallende Erscheinung. Gustave Michaud, der auf Veranlassung Picados eine chemische Untersuchung des Wassers vorgenommen hat, fand von Aschenbestandteilen nur $0,007 \mathrm{~g}$ im Liter. Das Fehlen von Fäulnisstoffen und irgendwie beträchtlichen Mengen von Salzen erklärt sich ans der Absorptionstätigkeit der Blätter. Um zu zeigen, daß die

1) L. Picado, Les Broméliacées épiphytes, considé rées comme milien biologique. Bulletin scientifique de la France et de la Belgique 1013, 7. Sér., T. 47, Fasc. 3 .

2) Vol, Sohtimper. Pflanzengeographie a:1 physio logiseher Grundlage. Jena 1898. B. 347 . 